\title{
Correction to: Curricular Advancement of Biomedical Engineering Undergraduate Design Projects Beyond 1 Year: A Pilot Study
}

\author{
Amir Manbachi (i), ${ }^{1,2}$ Elizabeth A. Logsdon, ${ }^{1}$ Youseph Yazdi, ${ }^{1}$ and Nicholas J. Durr ${ }^{1}$ \\ ${ }^{1}$ Department of Biomedical Engineering, Johns Hopkins University, 3400 N. Charles Street, Wyman Park Building, Suite 400 \\ West, Baltimore, MD 21218, USA; and ${ }^{2}$ Department of Neurosurgery, Johns Hopkins University, 600 N. Wolfe Street, Meyer \\ Building, Suite 8-181C, Baltimore, MD 21287, USA
}

\section{Correction to: Annals of Biomedical Engineering https://doi.org/10.1007/s10439-019-02434-7}

This erratum is to add author Nicholas J. Durr as a co-corresponding author.
Publisher's Note Springer Nature remains neutral with regard to jurisdictional claims in published maps and institutional affiliations.

Address correspondence to Amir Manbachi and Nicholas J. Durr, Department of Biomedical Engineering, Johns Hopkins University, 3400 N. Charles Street, Wyman Park Building, Suite 400 West, Baltimore, MD 21218, USA. Electronic mails: amir.manbachi@jhu.edu,ndurr@jhu.edu

The original article can be found online at https://doi.org/10. 1007/s10439-019-02434-7. 